\title{
Plasma coagulation profiles in patients with severe primary pulmonary hypertension
}

\author{
M.M. Hoeper*, M. Sosada+, H. Fabel*
}

Plasma coagulation profiles in patients with severe primary pulmonary hypertension. M.M. Hoeper, M. Sosada, H. Fabel. OERS Journals Ltd 1998.

ABSTRACT: Patients with primary pulmonary hypertension (PPH) benefit from treatment with anticoagulants, and histological findings suggest that in situ thrombosis of pulmonary vessels contributes to the pathogenesis of this disease. The mechanisms that cause a hypercoagulable state in the pulmonary vascular bed have not been fully investigated.

This study compared plasminogen plasma activity, protein $\mathrm{C}$ and protein $\mathrm{S}$ plasma activities, fibrinogen and fibrin degradation products (FGDP and FBDP, respectively), von Willebrand factor antigen (vWF-Ag), prothrombin fragment F1.2, thrombinantithrombin complexes (TAT), tissue plasminogen activator (tPA), and plasminogen activator inhibitor (PAI) in 16 patients with PPH and in 16 healthy volunteers. In a subset of the PPH patients, these variables were also compared in simultaneouslyobtained mixed-venous and arterial blood samples.

Proteins C and S, FGDP, FBDP, and plasminogen levels as well as plasma concentrations of prothrombin fragment F1.2 and TAT were normal in the 16 patients with PPH. In contrast, the plasma activity of PAI was significantly elevated $(p<0.0001)$. Arterial PAI levels were considerably higher than mixed venous PAI levels ( $p=$ 0.0018), which may reflect intrapulmonary production. Furthermore, vWF-Ag levels were significantly elevated $(\mathbf{p}<0.0001)$, but there was no significant difference between mixed-venous and arterial blood.

These data, on the whole, do not suggest increased thrombin activity in patients with primary pulmonary hypertension. However, the markedly elevated levels of plasminogen activator inhibitor as well as its transpulmonary gradient may provide a clue to locally impaired fibrinolysis in the pulmonary vascular bed.

Eur Respir J 1998; 12: 1446-1449.

Despite the fact that the lung circulation is a low-pressure system with regional low-flow zones, in situ thrombosis does not occur under physiological conditions, suggesting that the lungs have effective means of preventing intravascular coagulation. In contrast, thrombosis of pulmonary vessels is a common finding in primary pulmonary hypertension (PPH), where it is found with a frequency of $30-60 \%[1,2]$. These thrombotic events are likely to be involved in the progression of the disease since treatment with oral anticoagulants improves the prognosis for $\mathrm{PPH}$ patients $[3,4]$.

Data on the coagulation and fibrinolytic system in PPH are confusing. Previous studies in PPH patients found decreased fibrinolytic activity, as determined by a prolonged euglobulin lysis time [5]. Increased plasma levels of plasminogen activator inhibitor (PAI), which may be a cause of impaired fibrinolysis have been reported by some groups $[5,6]$, but not by others [7]. Increased thrombin activity in PPH was suggested by elevated plasma levels of fibrinopeptide A, a lysis product of thrombin fibrinogen cleavage [8]. Since fibrinopeptide A levels are highly sensitive to any form of instrumentation, it remains unclear whether this finding indeed reflects increased intravascular thrombin formation.
*Division of Pulmonary Medicine, Hannover Medical School, Hannover, Germany. +Division of Haematology and Oncology, Krankenhaus Siloah, Hannover, Germany.

Correspondence: M.M. Hoeper

Medizinische Hochschule Hannover

Division of Pulmonary Medicine

30623 Hannover

Germany

Fax: 495115323353

Keywords: Coagulation

fibrinolysis

plasma activator inhibitor

primary pulmonary hypertension

Received: October 201997

Accepted after revision August 61998
In the present study, a set of laboratory parameters for assessing anticoagulant and fibrinolytic activity in PPH was investigated. In a subset of patients, mixed-venous and arterial blood samples were also compared to determine any transpulmonary gradient of these variables.

\section{Patients and methods}

Sixteen patients with PPH, who were referred for evaluation of lung transplantation, were studied. In each case, the diagnosis was established according to the criteria proposed by the National Institutes of Health Registry on PPH [9]. All patients suffered from severe pulmonary hypertension, with marked elevations of mean pulmonary arterial pressure $(60.1 \pm 16.0 \mathrm{mmHg})$ and pulmonary vascular resistance $\left(1,509 \pm 594\right.$ dynes $\left.\cdot \mathrm{s} \cdot \mathrm{cm}^{-5}\right)$ as well as a severely depressed cardiac index $\left(1.6 \pm 0.4 \mathrm{~L} \cdot \mathrm{min}^{-1} \cdot \mathrm{m}^{-2}\right)$. The PPH patients were compared with a control group that consisted of 16 healthy volunteers, matched for age and sex.

\section{Medication}

Oral anticoagulants were replaced by s.c. heparin $2-4$ weeks prior to the study and heparin was stopped $24 \mathrm{~h}$ 
before the blood samples were obtained. Of the 16 patients, 10 had not received any anticoagulant drug before. All other medication was discontinued $12 \mathrm{~h}$ before the study began.

\section{Blood samples}

Blood samples from the PPH patients were obtained during a diagnostic heart catheterization. Mixed venous blood $(20 \mathrm{~mL})$ was carefully aspirated into tubes containing $3.8 \%$ sodium citrate from the distal (pulmonary arterial) opening of the Swan-Ganz catheter before the patients received heparin. Arterial blood $(20 \mathrm{~mL})$ was obtained through a femoral arterial line. Venous blood from the control group was obtained by venepuncture. The samples were immediately cooled on ice, centrifuged at $4^{\circ} \mathrm{C}$ and $1,500 \times g$ for 20 min and plasma aliquots were frozen at $-70^{\circ} \mathrm{C}$ until analysis.

In preparing this study, the question of whether the blood sampling site would affect the results of the coagulation tests was assessed. Twelve patients with congestive cardiomyopathy who underwent diagnostic right and left heart catheterization were investigated. Similar plasma levels of thrombin-antithrombin complexes (TAT), prothrombin fragment F1.2, fibrinogen and fibrin degradation products (FGDP and FBDP, respectively), tissue plasminogen activator (tPA), PAI-1, and von Willebrand factor antigen (vWF-Ag) were found when blood samples that were simultaneously obtained by direct venipuncture, through a Swan-Ganz-catheter and through an arterial line were compared (unpublished data).

\section{Plasma analysis}

The plasma was analysed routinely for the prothrombin time, the activated partial thromboplastin time, plasminogen plasma activity and protein $\mathrm{C}$ and protein $\mathrm{S}$ levels (Asserachrom ${ }^{\circledR}$ Protein $\mathrm{C}$ and Protein $\mathrm{S}$, respectively; Boehringer, Mannheim, Germany). Levels of vWF-Ag were determined by immunoelectrophoresis and expressed as a percentage of a standard value [10]. Commercially available enzyme-linked immunosorbent assays (ELISA) were used to assess the plasma concentrations of prothrombin fragment F1.2 (Behringwerke, Marburg, Germany), TAT (Behringwerke), tPA (Boehringer) and FBDP and FGDP (Organon Technika, Boxtel, The Netherlands). The PAI activity was measured using an amidolytic assay [11] based on the inhibition of tPA by PAI (Coatest ${ }^{\circledR}$; KabiVitrum, Stockholm, Sweden). The results were expressed as arbitrary units (AU), with $1 \mathrm{AU}$ of PAI inhibiting $1 \mathrm{IU}$ of tPA. All analyses were done in duplicate. Data from PPH patients were considered normal when they were within the $2 \mathrm{SD}$ range of the control group.

\section{Statistical analysis}

Statistical computations were performed using the Statview 512 program (Brainpower, Agoura Hills, CA, USA). Results are expressed as mean \pm SD. The unpaired t-test was used for statistical analysis unless noted otherwise.

\section{Results}

Mixed-venous blood samples from all 16 patients were analysed. The prothrombin time and the activated partial thromboplastin time as well as the plasminogen and protein $\mathrm{C}$ and $\mathrm{S}$ plasma activities were similar in the patient and the control group.

\section{Levels of von Willebrand factor antigen}

vWF-Ag levels were significantly elevated in the PPH patients. The mean level was $252 \pm 58 \%$ (range 185-385\%) in the PPH group versus $97 \pm 25 \%$ (range $50-130 \%$ ) in the control group $(\mathrm{p}<0.0001$; fig. 1$)$.

\section{Indicators of thrombin formation}

The plasma concentrations of F1.2 were normal in all $\mathrm{PPH}$ patients (mean $0.21 \pm 0.16 \mathrm{nmol} \cdot \mathrm{L}^{-1}$, range $0.03-0.52$ $\mathrm{nmol} \cdot \mathrm{L}^{-1}$ ) compared with the control group (mean $0.29 \pm$ $0.17 \mathrm{nmol} \cdot \mathrm{L}^{-1}$, range $\left.0.04-0.63 \mathrm{nmol} \cdot \mathrm{L}^{-1}\right)$. In addition, there was no detectable increase in TAT in the PPH group (mean $2.46 \pm 1.14 \mu \mathrm{g} \cdot \mathrm{L}^{-1}$, range $0.5-4.5 \mu \mathrm{g} \cdot \mathrm{L}^{-1}$ ) compared with the control group (mean $2.84 \pm 1.2 \mu \mathrm{g} \cdot \mathrm{L}^{-1}$, range $1.1-4.9$ $\left.\mu \mathrm{g} \cdot \mathrm{L}^{-1}\right)$.

\section{Indicators of fibrinolysis}

The plasma concentration of FBDP was elevated in two PPH patients $\left(1,058\right.$ and $3,039 \mu \mathrm{g} \cdot \mathrm{L}^{-1}$, respectively), while

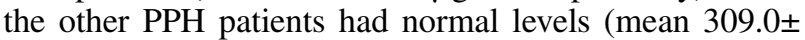
$72.8 \mu \mathrm{g} \cdot \mathrm{L}^{-1}$, range $200-420 \mu \mathrm{g} \cdot \mathrm{L}^{-1}$; control group: mean $339 \pm 92 \mu \mathrm{g} \cdot \mathrm{mL}^{-1}$, range $\left.180-489 \mu \mathrm{g} \cdot \mathrm{mL}^{-1}\right)$. The plasma concentrations of FGDP were also in the normal range in all but two patients in the PPH group (mean 318.2 \pm 98.2 $\mu \mathrm{g} \cdot \mathrm{L}^{-1}$, range $200-481 \mu \mathrm{g} \cdot \mathrm{L}^{-1}$; control group: $286 \pm 111$ $\mu \mathrm{g} \cdot \mathrm{mL}^{-1}$, range $\left.112-493 \mu \mathrm{g} \cdot \mathrm{mL}^{-1}\right)$. In the two patients with elevated concentrations of FGDP, the levels were only slightly increased, to 658 and $940 \mu \mathrm{g} \cdot \mathrm{L}^{-1}$, respectively.

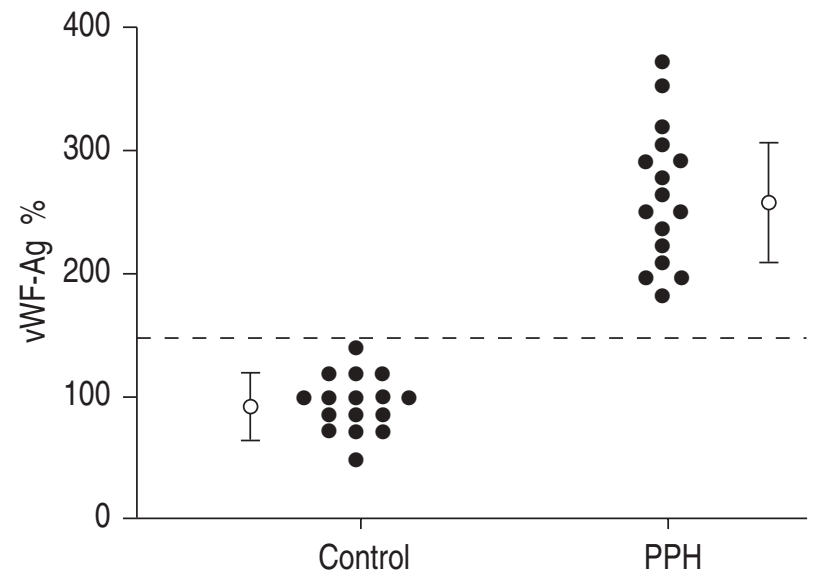

Fig. 1. - Levels of von Willebrand factor antigen (vWF-Ag) as a percentage of a standard value [10] in venous blood from 16 controls and 16 patients with primary pulmonary hypertension (PPH). The mean $( \pm \mathrm{SD})$ values are also shown $(\mathrm{O})$. - - - - indicates the upper normal limit. 


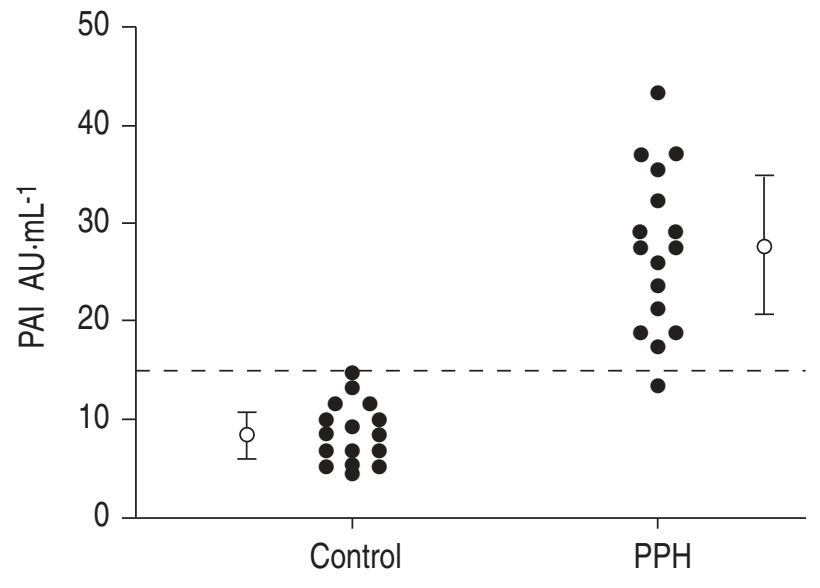

Fig. 2. - Plasminogen activator inhibitor (PAI) activity in venous blood from 16 controls and 16 patients with primary pulmonary hypertension $(\mathrm{PPH})$. The mean $( \pm \mathrm{SD})$ values are also shown $(\mathrm{O}) . \cdots$ - : indicates the upper normal limit. AU: arbitrary units.

The plasma concentration of tPA was marginally, but nonsignificantly $(\mathrm{p}=0.12)$ elevated in the PPH group (mean $11.5 \pm 4.1 \mathrm{ng} \cdot \mathrm{mL}^{-1}$, range $4.9-17.0 \mathrm{ng} \cdot \mathrm{mL}^{-1}$ ) compared with the control group (mean $7.8 \pm 1.8 \mathrm{ng} \cdot \mathrm{mL}^{-1}$, range $5.0-11.3$ $\mathrm{ng} \cdot \mathrm{mL}^{-1}$ ). The PAI activity (fig. 2) was significantly increased in $\mathrm{PPH}$ patients to $27.4 \pm 7.8 \mathrm{AU} \cdot \mathrm{mL}^{-1}$ (range 13.9 43.7 AU.mL-1, $\mathrm{p}<0.0001$ versus control group 9.2 \pm 2.9 AU.mL ${ }^{-1}$, range 5.4-15.1 AU.mL-1).

\section{Comparison of mixed-venous and arterial blood samples}

After the first interim analysis of the data, it was speculated that the elevated PAI levels might originate from increased PAI production in the pulmonary vascular bed. To address this question further, mixed-venous and arterial blood were simultaneously obtained from six patients. There were no remarkable differences in vWF-Ag, FBDP, FGDP, F1.2, TAT or tPA levels between mixed-venous and arterial blood. In contrast, PAI activity (fig. 3) was considerably higher in arterial than in mixed-venous blood samples $\left(44.7 \pm 7.22 \mathrm{AU} \cdot \mathrm{mL}^{-1}\right.$ versus $30.95 \pm 3.48 \mathrm{AU} \cdot \mathrm{mL}^{-1} ; \mathrm{p}=$ 0.0018 , paired t-test).

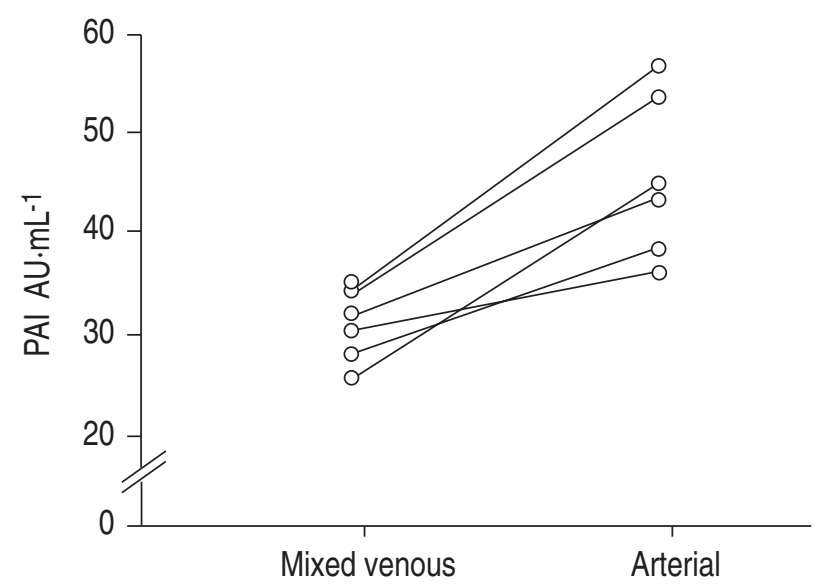

Fig. 3. - Plasminogen activator inhibitor (PAI) activity in simultaneously obtained mixed-venous and arterial blood samples from six patients with primary pulmonary hypertension. AU: arbitrary units.

\section{Discussion}

Previous studies have found evidence of increased thrombin activity and decreased fibrinolysis in PPH [5-8]. EISENBERG et al. [8] reported elevated plasma levels of fibrinopeptide A in 19 of 27 patients with PPH. Fibrino-peptide A is a cleavage product of fibrinogen, formed by the action of thrombin, and thus, may serve as an indica-tor of thrombin activity. In the present study, however, the normal plasma concentrations of F1.2 and TAT suggest that increased thrombin formation is not commonly pre-sent in $\mathrm{PPH}$. Free thrombin, in plasma, is practically undetectable by the techniques currently available because of its short half-life [12]. Therefore, the clinical assessment of intravascular thrombin production relies on indirect approaches. Both TAT and prothrombin fragment F1.2 reliably reflect thrombin formation $[12,13]$ and seem to be less susceptible than fibrinopeptide A to manipulation, as reflected by the normal results in all patients in this study. In a recently published report from the Pulmonary Hypertension Center in Denver (CO, USA), F1.2 and TAT were also normal in patients with PPH or secondary pulmonary hypertension [5].

Impaired fibrinolysis has been repeatedly reported in patients with PPH [5-7]. In view of the essentially normal plasma levels of plasminogen and tPA, the finding that the PAI activity was significantly increased in the PPH group may provide an explanation for the impaired fibrinolysis in PPH. It is not clear, however, whether the increased PAI activity reflects increased PAI formation in the pulmonary vessels. Based on immunological assays, at least four different peptides that exert PAI activity can be identified [14]. Of these, most of the plasma PAI activity is attributed to PAI-1 (formerly called endothelial cell-type PAI). PAI-1 can be synthesized by endothelial cells, platelets and hepatocytes [15]. The finding that PAI activity was significantly higher in arterial than in mixed-venous blood supports the assumption that the increased PAI activity reflects increased production of PAI-1 in the pulmonary vascular bed.

The interpretation of increased vWF-Ag levels in PPH is equally hampered by confounding factors. vWF-Ag is stored in platelets, megakaryocytes and endothelial cells and is released during various forms of vascular injury as well as during the coagulation process, platelet activation, or inflammation [16]. It is likely that the increased release of vWF-Ag in PPH occurs in the pulmonary vascular bed, which is exposed to high shear stress and inflammation; however, in the present study, vWF-Ag concentrations were no different between arterial and mixed-venous blood. It is not known whether increased plasma concentrations of vWF-Ag have any pathophysiological consequences. For theoretical reasons, high levels of circulating vWF-Ag could lead to intravascular activation of platelets via glycoprotein Ib/IX receptors. In support of this hypothesis, GEGGEL et al. [17] described increased plasma ristocetin cofactor activity in patients with $\mathrm{PPH}$, which indicates an increased ability of vWF-Ag to aggregate platelets. In the study by GEGGEL et al. [17], however, vWF-Ag levels were essentially normal in the six PPH patients investigated.

A potential limitation for the interpretation of the data is the fact that samples from PPH patients and controls were obtained differently. Mixed-venous blood from PPH 
patients was obtained through a right heart catheter, whereas peripheral blood from controls was obtained through venepuncture. However, as noted in the Methods section, prior to this study, a comparison was made of the impact of the blood sampling technique on the coagulation parameters evaluated here and no differences were found between the two techniques.

In conclusion, the normal plasma levels of prothrombin fragment F1.2 and thrombin-antithrombin complexes found in the patients with primary pulmonary hypertension argue against increased thrombin formation. The increased plasminogen activator inhibitor activity may account, at least partly, for the impaired fibrinolytic activity that has been described previously.

\section{References}

1. Wagenvoort CA, Wagenvoort N. Primary pulmonary hypertension: a pathologic study of the lung vessels in 156 clinically diagnosed cases. Circulation 1970; 42: 11631184.

2. Bjornsson J, Edwards WD. Primary pulmonary hypertension: a histopathologic study of 80 cases. Mayo Clin Proc 1985; 60: 16-25.

3. Rich S, Kaufman E, Levy PS. The effect of high doses of calcium-channel blockers on survival in primary pulmonary hypertension. $N$ Engl J Med 1992; 327: 76-81.

4. Fuster V, Steele PM, Edwards WD, Gersh BJ, McGoon MD, Frye RL. Primary pulmonary hypertension: natural history and the importance of thrombosis. Circulation 1984; 70: 580-587.

5. Welsh CH, Hassell KL, Badesch D, Kressin DC, Marlar RA. Coagulation and fibrinolytic profiles in patients with severe pulmonary hypertension. Chest 1996; 110: 710717.

6. Boyer-Neumann C, Brenot F, Peynaud-Debayle E, et al. Continuous infusion of prostacyclin decreases plasma levels of t-PA and PAI-1 in primary pulmonary hypertension. Thromb Haemost 1995; 4: 727-738.

7. Huber K, Beckmann R, Frank H, Kneussl M, Mlczoch J, Binder BR. Fibrinogen, t-PA and PAI-1 plasma levels in patients with pulmonary hypertension. Am J Respir Crit Care Med 1994; 150: 929-933.

8. Eisenberg PR, Lucore L, Kaufman E, Sobel BE, Jaffe AS, Rich S. Fibrinopeptide A levels indicative of pulmonary vascular thrombosis in primary pulmonary hypertension. Circulation 1990; 82: 841-847.

9. Rich S, Dantzker DR, Ayres SM, et al. Primary pulmonary hypertension: a national prospective study. Ann Intern Med 1987; 107: 216-223.

10. Laurell CB. Quantitative estimation of proteins by electrophoresis in agarose gel containing antibodies. Anal Biochem 1966; 15: 45-52.

11. Chmielewska J, Ranby M, Wiman B. Evidence for a rapid inhibitor to tissue plasminogen activator in plasma. Thromb Res 1983; 31: 427-443.

12. Pelzer H, Schwartz A, Heimberger N. Determination of human thrombin-antithrombin III complex in plasma with an enzyme-linked immunosorbant assay. Thromb Haemost 1988; 59: 101-106.

13. Pelzer H, Schwartz A, Shiber W. Determination of human prothrombin activation fragment $\mathrm{F} 1$ and 2 in plasma with an antibody against a synthetic peptide. Thromb Haemost 1991; 65: 153-159.

14. Hekman CM, Loskutoff DJ. Fibrinolytic pathways and the endothelium. Semin Thromb Hemost 1987; 13: 514 527

15. Sprengers ED, Kluft C. Plasminogen activator inhibitors. Blood 1987; 69: 381-387.

16. Sporn LA, Marder VJ, Wagner DD. Inducible secretion of large, biologically potent von Willebrand factor multimers. Cell 1986; 46: 185-192.

17. Geggel RL, Carvalho ACA, Hoyer LW, Reid LM. Von Willebrand factor abnormalities in primary pulmonary hypertension. Am Rev Respir Dis 1987; 135: 294-299. 